Brit. Heart F., 1967, 29, 268.

\title{
Absent Inferior Vena Cava, Symmetrical Liver, Splenic Agenesis, and Situs Inversus, and their Embryology
}

\author{
MAURICE CAMPBELL AND D. C. DEUCHAR \\ From the Cardiac Department, Guy's Hospital, London S.E.1, and the Institute of Cardiology, London W.I
}

Several cardiac malformations are known to be associated with situs inversus (Ivemark, 1955; Campbell and Deuchar, 1965, 1966). In addition, there are often some venous and visceral malformations, e.g. bilateral superior venæ cavæ (SVC), absence of a segment of the inferior vena cava (IVC), agenesis of the spleen, and symmetry of the liver. We shall discuss these five malformations, particularly the correlations between them, and whether their embryological development provides any explanation for the correlations.

Until the past 25 years many malformations of the veins were known only from specimens seen at necropsy or in the dissecting room, since as a rule they produce no symptoms. Bilateral SVC provide one example. Campbell and Deuchar (1954) described 40 such cases as well as 6 where a persistent left SVC was the only one. In general, a left SVC alone is a rare malformation, but most of these 6 examples occurred with complete situs inversus, where it is the normal finding.

More recently we have discussed the relation of situs inversus and splenic agenesis and the relation of these two with bilateral SVC (Campbell and Deuchar, 1966). The discussion in that paper should, we think, be referred to, since we have tried to avoid repetition from it in this one.

Absence of a segment of the IVC, so that most of the blood from the lower part of the body reaches the heart through the azygos vein and the SVC, is another example, and is not very uncommon. For brevity we shall refer to this as "absent IVC" though it is only the greater part of the prerenal segment that is missing. The resulting changes in the circulation were better known as a result that followed thrombosis in this part of the IVC secondary to a growth or some other obstruction.

Received July 20, 1966.

\section{Absent Inferior Vena CAVA}

Wardrop Griffith, as early as 1891 , reported such a case with complete situs inversus, a common ventricle, and pulmonary atresia also. He thought the most remarkable feature was that the drainage from the lower part of the body was through a large azygos vein, and that only the hepatic vein entered the atrium at the site where the IVC usually does. In 1901, Dwight collected 20 reported cases of absent IVC, one of which was found at necropsy in a man of 91 with no other malformation of the heart.

McClure and Butler (1925), in a paper dealing mainly with the development of the IVC in man, described several of the malformations to which it is liable. They thought the commonest were (1) persistence of the right and left supracardinal veins ${ }^{\star}$, 64 cases; (2) absence of the prerenal part of the IVC and its replacement by the supracardinal* vein (absent IVC), 35 cases; and (3) persistence of the left supracardinal vein, 18 cases. In the cat, with which they were making comparisons, the posterior cardinal veins persist normally till a much later stage of development than in man, and so malformations due to their persistence were much more common. In man, they thought it very rare for the posterior cardinal vein to persist, but a probable example of this has been reported recently by Kark (1963).

In a later review of malformations of the IVC, McClure and Huntington (1929) included five examples of absent IVC in mammals, reported by

* Hamilton, Boyd, and Mossman (1962) do not use the term "supracardinal vein", but Gray's Anatomy (1962) uses it as the equivalent of their-lateral sympathetic system. Here it must have been used as the equivalent 268 
Stark as early as 1835. Latimer and Virden (1944) speak of "complete absence" of the IVC in the title of their case report, but the text makes it clear that the malformation was of the usual type.

Cases Recognized by Angiocardiography. Our attention was first drawn to this condition by catheterization and angiocardiography through the femoral vein in a small boy with isolated lævocardia, a bilocular heart, and absence of the spleen (Campbell, Gardner, and Reynolds, 1952). When Campbell and Deuchar (1954) wrote about persistence of the left superior vena cava we described 4 cases with an absent IVC, all with complete or partial situs inversus and, therefore, included in our recent paper (Campbell and Deuchar, 1966, Cases 7, 26, 44, and 48). They suggested that an abnormal situs of the viscera made it more difficult for the several components, from a venous system that was originally bilateral and symmetrical, to join together normally to form the definitive IVC.

About this time Stackelberg, Lind, and Wegelius (1952) reported 2 cases among 100 where the contrast medium for angiocardiography had been injected through the veins of the leg. Downing (1953) also reported 2 cases, one with lævocardia and the liver on the right but with the stomach and spleen also on the right.

Since then the absent IVC has been recognized more often, especially when angiocardiography or catheterization were carried out through the femoral or internal saphenous veins. In the past few years it has become of practical importance when operations are carried out using extracorporeal circulation, and has been looked for and found even more frequently.

Anderson, Adams, and Burke (1961) collected 41 cases, including 16 of their own. In 20 of them, there was normal situs of the heart and viscera, but in 18 there was some form of situs inversus (and in 7 at least this was incomplete). We have not found in their paper any reference to the asplenia syndrome or to a symmetrical liver. They thought the incidence of an absent IVC was 0.6 per cent among patients with malformations of the heart.

Muelheims and Mudd (1962) reported 8 personal cases among 600 which had cine-angiocardiography after an injection through the long saphenous or femoral veins, an incidence of 1.3 per cent. All these had normal situs of the viscera. A ninth case had a normal IVC but a large vein (persistent supracardinal) from the renal part of the IVC to the left SVC.

Dupuis, Nuyts, and Christiaens (1964) reported 5 cases, 1 with dextrocardia and 4 with normal situs, including 1 without any other malformation of the heart. Ongley et al. (1965) have recently described 5 cases with multiple spleens, the anomalous (absent) IVC system, and anomalous pulmonary venous drainage: 3 had isolated lævocardia, 1 situs inversus, and only 1 a normal situs.

Campbell and Deuchar (1966) have now reported 10 examples among 49 cases with complete or partial situs inversus (the first 4 of them have been included by Anderson et al., 1961). All our indexed cases had some degree of situs inversus and we can find only 2 others with a normal situs, but it is possible that some more may have been overlooked.

From all these personal and reported cases of an absent IVC there were 35 with a normal situs of the viscera and 29 with complete or partial situs inversus. Obviously, therefore, its incidence in situs inversus is enormously higher than in those with normally placed viscera. On the available evidence, its incidence among all those with a malformation of the heart is of the order of 1 per cent, and among those with situs inversus about 20 per cent. Possibly this last figure is too high, since we find no reference to the syndrome in the cases of Van Praagh et al. (1964) with dextrocardia.

In the presence of the asplenia syndrome, the incidence of an absent IVC is still higher. Thus, Campbell and Deuchar found it in 6 of $13(46 \%)$ of those with the asplenia syndrome and partial or complete situs inversus and in 4 of the $36(11 \%)$ with situs inversus without evidence of the asplenia syndrome.

Before discussing the complicated embryological development of the IVC, we wish to say something about the less well-known condition of symmetry of the liver, and about the correlations between these conditions.

\section{SYMMETRY OF THE LIVER}

In his description of the asplenia syndrome, Ivemark (1955) emphasized the frequency with which the liver was relatively symmetrical, with lobes of about equal size on each side and the gallbladder centrally placed or on either side. This was so in at least 45 per cent of his cases. This has been confirmed by Van Praagh et al. (1964) and by several others. In the complete syndrome there is no trace of splenic tissue, but cases with small multiple spleens show many of the same features of relative symmetry, and form a group that is closely related to, and often included with, the asplenia syndrome (Ivemark, 1955).

Among our 49 cases with complete or partial situs inversus (Campbell and Deuchar, 1966) there were 8 or possibly 9 with relative symmetry of the liver. All these, however, were found among the 
TABLE

INCIDENCE OF FIVE MALFORMATIONS AND OF ALL MALFORMATIONS OF THE HEART IN THE GROUPS SHOWN IN FIRST COLUMN

\begin{tabular}{|c|c|c|c|c|c|c|}
\hline \multirow[b]{2}{*}{$\begin{array}{c}\text { In series of cases of groups shown } \\
\text { below }\end{array}$} & \multicolumn{6}{|c|}{ Percentage incidence of malformations below } \\
\hline & $\begin{array}{c}\text { Situs } \\
\text { inversus }\end{array}$ & $\begin{array}{l}\text { Bilateral } \\
\text { SVC }\end{array}$ & $\begin{array}{l}\text { Agenesis } \\
\text { of spleen }\end{array}$ & $\begin{array}{l}\text { Symmetry } \\
\text { of liver }\end{array}$ & $\begin{array}{l}\text { Absent } \\
\text { IVC }\end{array}$ & $\begin{array}{l}\text { All cardiac } \\
\text { malformations }\end{array}$ \\
\hline $\begin{array}{l}\text { General population } \\
\text { Situs inversus } \\
\text { (a) with probable splenic agenesis } \\
\text { (b) without splenic agenesis } \\
\text { Situs inversus (all) } \\
\text { Bilateral SVC } \\
\text { Agenesis of spleen } \\
\text { Symmetry of liver } \\
\text { Absent IVC }\end{array}$ & $\begin{array}{l}0.02 \\
- \\
- \\
30 \\
75 \\
85 \\
45\end{array}$ & $\begin{array}{l}0 \cdot 3 \\
31 \\
22 \\
24 \ddagger \\
\frac{28}{25} ? \\
50\end{array}$ & $\begin{array}{c}<0 \cdot 17^{\star} \\
\text { All } \\
0 \\
25 \ddagger \\
25 \\
100 ? \\
60\end{array}$ & $\begin{array}{c}\text { Very small } \\
69 \\
0 \\
15 \ddagger \\
25 \\
45-70 \\
\frac{40}{40}\end{array}$ & $\begin{array}{l}\text { Very small } \dagger \\
\begin{array}{l}46 \\
11 \\
20 \ddagger \\
33^{\star \star} \\
46^{\star \star} \\
60 \\
-\end{array}\end{array}$ & $\begin{array}{c}0.6 \\
\overline{-} \\
20 \\
4 ? \\
65-94 \\
\text { Nearly all } \\
\text { Not known }\end{array}$ \\
\hline
\end{tabular}

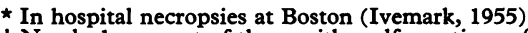

+ Nearly 1 per cent of those with malformations of the heart.

$¥$ These figures show the percentage in the 20 per cent with malformations.

28 per cent (Ivemark, 1955), 24 per cent (Van Praagh et al., 1964), and 33 per cent (Campbell and Deuchar, 1966).

$\star \star 6$ out of 13 of our cases.

13 cases that were probably examples of the asplenia syndrome; so that it seems closely related to this rather than directly to the situs inversus. We could not remember reading anything about symmetry of the liver or seeing an example of the condition except in connexion with the asplenia syndrome. This is also the experience of several pathologists whom we have asked about it, and we can find no reference to the subject in such a recondite book as that of Willis (1962). Symmetry of the liver must be very rare except with the asplenia syndrome and situs inversus.

Nevertheless, one of us (D.C.D.) recently found a Guy's Hospital necropsy report of such a liver in a small backward infant of 16 months, with a normally-placed spleen and only a few of the features of situs inversus. A barium meal showed partial malrotation of the bowel and the report concluded that the liver lay transversely across the abdomen. At necropsy, both these findings were confirmed. (1) The liver lay in a transverse position with the left lobe under the left and the right lobe under the right diaphragm. (2) The mesentery was imperfectly rotated, lying transversely between the coliac axis and the origin of the renal arteries. Most of the gut was in the right side of the abdomen and the large gut was on the left side with the crcum in the position of the middle part of the transverse colon. (3) The systolic murmur heard in life was found to be due to a fairly large ostium secundum atrial septal defect. The spleen and stomach were both said to be normal and normally placed.

It is, of course, true that the liver develops as a symmetrical organ and remains so for a considerable part of fœtal life, till 63 days (Hamilton et al., 1962). This is not true of the venous systems connected with the liver. Its later asymmetry may be due to the asymmetrical development of its venous systems (see p. 273), though this is not usually given as the explanation.

\section{SOME CORRElations of These Malformations}

Symmetry of the liver, an absent IVC, and bilateral SVC all show a high correlation with situs inversus and the first two an even higher one with agenesis of the spleen (see Table). None of these malformations is very common. Probably bilateral SVC are the most common, as they were found in 0.3 per cent of unselected series of over 3000 cadavers (Sanders, 1946). The incidence of situs inversus in Norway is 1 in 10,000 (Torgersen, 1950) and, including its incomplete forms, this is probably increased to about 1 in 5000 (Campbell, 1963). Splenic agenesis was found in 1 of each 586 hospital necropsies at Boston (Ivemark, 1955) and this would be much higher than in the general population. If, therefore, they all had an unrelated chance distribution, it would be rare to find a patient with any two of them (less than 6 in a million). The figures shown in the Table are, therefore, highly significant, though they are rough estimates, shown as percentages only for convenience of comparison.

The top line of the Table shows the incidence of these five malformations in the general population. Subsequent lines and columns show the incidence of each malformation and of all cardiac malformations in series of subjects selected because they had one of the malformations shown in the first column. For situs inversus they are taken mainly from the 49 cases of Campbell and Deuchar (1965, 1966), for bilateral SVC from the 40 cases of Campbell and Deuchar (1954), and for agenesis of the spleen from the 69 cases of Ivemark (1955), though other 
sources have been used where available, e.g. Van Praagh et al. (1964). For symmetry of the liver and absent IVC the numbers are very small (about 12 cases).

The high correlations, e.g. the fact that half our cases with absent IVC have bilateral SVC, are highly significant and prove some causal connexion in view of their relative or extreme rarity. The numbers are, however, rough estimates and are too small for us to know if there is any significant difference between, say, 40 and 60 per cent.

About one-fifth of all cases of situs inversus have other malformations of the heart (Campbell, 1963), and each one of the other four malformations discussed was found in between 15 and 25 per cent of this one-fifth, often more than one in the same subject.

Probably bilateral SVC occur without any other malformations more often than the other groups discussed. The 4 per cent with other malformations is calculated from the known incidence of bilateral SVC $(0.3 \%)$ and of all malformations of the heart $(0.6 \%)$, and the fact that bilateral SVC occur in 2 per cent of those with all malformations of the heart. There is a fairly high correlation with the other four malformations discussed, between 25 and 33 per cent.

Between 65 and 94 per cent of the cases of agenesis of the spleen have other malformations of the heart. The higher figure based on Ivemark (1955) is certainly nearer our experience and probably more accurate, but the lower figure is given by Willis (1962, quoting from Putscher and Manian). Threequarters of these have complete or partial situs inversus. The evidence for the incidence of symmetry of the liver (45-70\%) is less complete, but the lower figure may simply be due to the assumption that the liver was normal in several cases where there was no specific statement about its position. The figure for the incidence of bilateral SVC in this group is more reliable than that of an absent IVC, but the higher figure for the latter may be correct.

Symmetry of the liver has not so far as we know been discussed except with agenesis of the spleen, and rarely occurs without this. It must, therefore, be highly correlated with situs inversus also. It appears to be more highly correlated with an absent IVC than with bilateral SVC, but the numbers are too small to be sure of this.

We do not know the incidence of an absent IVC in the general population, though Seib (1934) found bilateral post-renal IVC in 3 per cent and a left IVC alone in 0.5 per cent. Since an absent IVC occurs in about 1 per cent of those with all malformations of the heart, it may be about half as com- mon as bilateral SVC. Of those with an absent IVC about half have agenesis of the spleen $(60 \%)$, bilateral SVC (50\%), situs inversus (45\%), and symmetry of the liver $(40 \%)$. The numbers are not large enough for us to know if these differences are significant, but, considering the rarity of an absent IVC, the correlations certainly are.

These close correlations between five relatively rare malformations cannot be due to chance. It follows that there must be some common cause or that one of them must be at least a partial cause of the others. The times in embryological life when these conditions develop will be considered, though the times when an organ develops and when a malformation of it is caused are not necessarily the same. Generally, however, the cause must act at or before that time.

We shall find that situs inversus is decided before the first visible signs of asymmetry of the heart at 25-26 days, certainly by the third week and much earlier if there is a genetic cause. The development of the spleen, the normal asymmetry of the liver, and the combination of the different parts to form the IVC are all decided later than this, probably between the 33rd and 36th days of embryonic life. The persistence of bilateral SVC is settled still later.

\section{The Production of Situs Inversus in ANIMALS}

Some of the fundamental experimental work has been accepted for a long time. Spemann in 1906, Pressler in 1911, and Spemann and Falkenberg in 1919 (all quoted by Bacon, 1945) showed that in Triton and Rana normal asymmetry was located in the roof of the gut. Removal of a square area from the dorsum of the embryo, half way down the back, and its rotation through $180^{\circ}$ resulted in situs inversus of the heart and other viscera.

This suggests that the causes of situs inversus are acting at a very early stage. Obviously, there is no gross rotation of this type when the condition is found in man, but an inherent biochemical abnormality of one side or some environmental factor acting on one side only might lead to an unbalanced development of the other side and so might produce the same effect.

The later experimental work has been concerned more with the production of double hearts. Ekman (1924) showed that in Bombinator normal double hearts often developed when the fusion of the primitive bilateral endocardial heart tubes was prevented. Copenhaver (1926) extended this last work and showed that when the median area of the cardiac rudiment in Amblyostoma punctatum was removed, 
thus splitting the cardiac rudiment into two parts, the left part developed a normal heart and the right part a heart that was sometimes inverted. More generally, he showed that when the part of the mesoderm which normally forms the heart was extirpated before stage 29 (shortly before pulsation begins in stage 33), the surrounding mesoderm could develop a normal heart; but this did not happen if a larger part was removed and replaced by mesoderm and ectoderm from the flank. Transplants in stages 25-29 gave normal hearts when the anterior part of the transplant was placed anteriorly, but reversed hearts with pulsation in the wrong direction when the anterior part was placed posteriorly. Copenhaver concluded that the heart was an equipotential system in the sense that (a) any part as large as a half could develop into a whole heart; (b) one rudiment could be made to form two functional hearts; and (c) two rudiments could be made to form one functional heart.

Goss (1935), using 9-day-old rat embryos, showed that similar results could be obtained in mammals as well as in amphibians. By mechanical prevention of the union of the two lateral cardiac primordia, double hearts could be produced and these tended to be mirror images of each other. He thought that the mammalian heart was self-differentiating, and that this power of differentiation was directed more to function than to form.

Bacon (1945) found that explants and gastrocele implants of heart mesoderm from stage 11 of Amblyostoma (but not earlier) could differentiate into normal hearts. Removal of the archenteron floor showed that the endothelium of this part was important, since two hearts developed, one on each side of the extirpated area. Generally the heart on the left was better developed and that on the right showed situs inversus.

Fales (1946) confirmed that the two halves of the heart anlage of Amblyostoma each developed a more or less normal heart, when separated by an inserted block of tissue at stages 14-15. She found the heart on the left was normally positioned, and the one on the right was inverted in 9 of 11 cases; but many of the hearts in her series showed other malformations, and she thought this was sometimes caused by pressure of the graft. She emphasized that neither of these double hearts ever formed a connexion with the contralateral arteries and veins, though both often, but not always, produced an adequate circulation with the vessels of their own side.

Here too, the experimental evidence suggests that situs inversus is determined at a very early stage before the fusion of the right and left dorsal endocardial heart tubes. There is no reason to think that these results in animals are not equally applicable to man, and this would mean that a normal or inverted situs in man is settled in or before the third week. This is several days before the first appearance of asymmetry at 25-26 days.

At this stage the heart tube becomes longer than the cavity in which it lies; it forms a U-shaped bend at the groove between the bulbus and the ventricle, so that the bulbo-ventricular mass points downwards (caudally) and to the right. There is a second stage of asymmetry at 30-32 days, when the left horn of the sinus venosus becomes separated from the left side of the atrium; and the right horn and the right side of sinus venosus grow more quickly so that both horns and the sinus connect only with, and later become incorporated in, the right atrium.

There is, of course, no question of double hearts, one of which has disappeared, in ordinary situs inversus, but a mechanism that prevents the junction of the two endocardial heart tubes might destroy the left-sided one and allow the right-sided one to develop an inverted heart. Admittedly, Fales (1946) found that the two hearts made no connexion with the contralateral arteries and veins, but on hæmodynamic grounds, if on no other, this would be unlikely to apply when only one of the hearts continued to exist.

Possibly, these double hearts, one with a normal position and one with situs inversus, could also be pertinent in considering monozygotic twins where, as is the usual finding in such pairs (Campbell, 1961), one has a normal heart and the other a heart with situs inversus. This would be pertinent only if the early division of the single ovum could in some way have the same effect as the much later forcible isolation of the two primitive cardiac tubes. Even then, there are many cases where both of a pair of monozygotic twins do have situs inversus.

The observational side of embryology can say only that the time of origin of any malformation must be on or before a certain date. For situs inversus this is the first appearance of the asymmetry that could be its basis. If the cause is genetic, it was settled from the start, though there may be no manifest sign of it till much later. When situs inversus appears in animals without experimental interference with the embryo, there is some evidence of a genetic cause. Thus, Tihen, Charles, and Sippel (1948) found that it was common in certain inbred strains of mice, though uncommon in all others; and Baker-Cohen (1961) found the same thing in certain strains of platyfish. Both these authors thought there was recessive Mendelian inheritance with incomplete penetrance, and Campbell (1963) brought forward evidence that this was the case in man also. 


\section{DeVELopment of SPLeEN, Liver, AND INFERIOR Vena CAVA}

Development of the Spleen. The spleen arises as a mass of mesodermal cells on the left side of the dorsal mesogastrium above the cardiac end of the stomach, substantially in the mid-line. It gradually becomes vascularized and the capillaries dilate to form the sinusoids. Hamilton et al. (1962, p. 256) place its first appearance in human embryos of 10 mm. crown-to-rump (CR) length, i.e. about 36-37 days.

Ivemark (1955) studied this period carefully and placed it a day or two earlier. Some specimens show early angiogenesis in Streeter's Horizon $X V$ (corrected to 34-35 days). All specimens show this and most show some sinusoids in Horizon $X V I$ (36-37 days). Ivemark showed that the conotruncal malformations, so constantly associated with splenic agenesis, developed only a day or two later, and used this as an argument that they were caused by the same factor.

Splenic agenesis must, therefore, be settled before the 34th or, at latest, the 36th day. Its later development and migration to the left side are hardly pertinent.

Development of the Liver and its Veins. The hepatic rudiment appears about the 14-somite stage, 25-26 days, as a bud from the wall of the duodenum. The larger cranial part of this bud divides into right and left masses which extend into the mesenchymal tissue of the septum transversum to form the endodermal part of the liver. Later they become interlaced with the vitelline and umbilical veins (Hamilton et al., 1962, p. 240).

At 30 days $(4 \mathrm{~mm}$. CR) the right and left vitelline veins are still symmetrical on either side of the liver. They form many plexiform anastomoses and come in close contact with the liver cells, forming the hepatic sinusoids. Anterior to the liver, they still enter the sinus venosus as the right and left hepatocardiac channels (Hamilton et al., 1962, p. 190). Later, most of the left vitelline vein and the distal part of the right disappear, the remainder of the right becoming the portal vein. The left hepatocardiac channel also disappears and the right channel becomes the terminal part of the IVC.

The right and left umbilical veins (lateral to the vitelline veins) are still symmetrical at 30 days. They also become incorporated in the substance of the liver (a little later than the vitelline veins) so that all the blood from the yolk sac and the placenta reaches the liver cells before the general circulation. At about 33 days (6-7 mm. CR) the right umbilical vein atrophies. The hepatic sinusoidal communica$\mathrm{T}^{*}$ tion between the left umbilical vein and the right hepato-cardiac channel enlarges and forms the ductus venosus.

As a result of these changes, the main blood flow is directed towards the right upper quadrant of the liver. Fig. 187c in Gray's Anatomy (1962) shows this clearly and shows the right side as larger, though Hamilton et al. (1962) say that at the $35 \mathrm{~mm}$. stage (63 days) the liver substance is still symmetrical. The veins have long ceased to be symmetrical.

It is, therefore, possible that the greater blood flow to the right dome from about the 33rd day may be, partly at least, responsible for the asymmetry of the liver, though this does not become manifest till much later, and we are not aware that it has been suggested as the cause.

Development of the IVC. There is less risk of a malformation when a structure develops from a single precursor than when it develops from several precursors. This is the case with the IVC which develops from parts of several separate venous systems that have to combine-the posterior cardinal, the lateral sympathetic, and the subcardinal veins, and the hepato-cardiac channel, itself developed from the vitelline vein. Many of these veins are, however, plexiform in their earlier stages, and the branches that carry most blood will enlarge and become the final channel. This hæmodynamic effect of the blood flow will help to produce the final continuity.

The fact that all these systems were originally bilateral and symmetrical and that the definitive channel is unilateral and right-sided does not increase the difficulty greatly, because all the parts come from the member of the pair on the same side-the right side normally and the left side when there is complete situs inversus. If, however, there is some failure to decide which side is to be dominant for this purpose, some parts might fail to connect up and so disappear.

In cases of "absent IVC" the right hepatocardiac channel still persists as the right hepatic vein. The part that is missing is the segment between the right hepato-cardiac channel and the subcardinal vein (and perhaps part of this vein itself). This segment develops from a plexus connecting the right subcardinal vein and the hepatic sinuses, generally in the 7-8 $\mathrm{mm}$. CR embryo of 34-35 days. Almost certainly, the critical period for the "absent IVC" is from 33-36 days, though the changes in the abdominal venous systems that produce the final IVC cover a long period from 25 to 50 days, mainly between 29 and 41 days.

Bilateral SVC following persistence of the left anterior cardinal vein is well recognized. We were 
surprised to find that it is settled so much later than the other venous changes discussed. Hamilton et al. (1962, p. 192) place it in the $22 \mathrm{~mm}$. CR stage, i.e. at $48-50$ days.

\section{Conclusions}

The close correlations in the incidence of these conditions suggest that they have some common cause. Three of them probably develop between the 33rd and 36th days of embryonic life. They might, therefore, be caused by some teratogenic agent acting at or shortly before this time. It is not easy to see anything they have in common except their dependence on a blood supply that was changing from being symmetrical to asymmetrical. It seems more likely that situs inversus, which is decided on at an earlier stage of development, is a predisposing cause.

In addition to the subjects with complete situs inversus there are (1) others with the abdominal viscera inverted but with the heart normally placed, (2) others with only the heart inverted, and (3) others where it is difficult to be sure whether the abdominal viscera are inverted or not-the asplenia group of Van Praagh et al. (1964).

It is not hard to see how bilateral SVC or an absent IVC might be caused by any uncertainty about whether the situs is to be normal or inverted. At first, it seemed hard to see how this could make a symmetrical liver more likely. The development of the liver with its larger blood flow to the right side does, however, suggest a possible mechanism, provided this larger flow is, in fact, the cause of the right side becoming larger at a later stage. The venous return to the atria has an important effect on their development and we think this is the case with the liver also.

Splenic agenesis seemed even more difficult. But if the mesodermal cells that are to form the spleen lie (as normally) on the left side of the mesogastrium and, because of uncertainty about the situs, its projected blood vessels lie on the right side, the two could fail to meet. Under these conditions the spleen might never develop, since Willis (1962) writes, "it is essentially part of the cardiovascular system".

This could explain also why subjects with multiple small spleens can reasonably be grouped with those who have no spleen (Ivemark, 1955). They could be the same from the aspect of the heart and its malformations though not from the aspect of splenic function. If the splenic primordia and its projected blood supply were on different sides, small parts of the primordia might find casual blood supplies that enabled them to develop into small independent spleens.
So much emphasis has been put on the asplenia syndrome (Ivemark, 1955; Van Praagh et al., 1964) that it has almost seemed it was looked on as the cause of the uncertainty of the situs of the abdominal viscera. We think the uncertain situs is the cause of the splenic agenesis or multiple small spleens and of the symmetrical liver.

\section{SUMMARY}

The conditions found when there is a break in the normal inferior vena cava with drainage through the azygos vein (absent inferior vena cava) have been described.

There are close associations in the incidence of situs inversus, bilateral superior vena cava, the absent inferior vena cava, agenesis of the spleen, and symmetry of theliver, and especially between the last three.

Four-fifths of the subjects with complete situs inversus appear to be normal in every other way, but one-fifth have other malformations of the heart. The other four malformations we are discussing each occur in about one-quarter of this last group. More than half of those with splenic agenesis, symmetry of the liver, or an absent inferior vena cava, have also one or both of the remaining two malformations.

Experimental work on animals shows that whether the situs is normal or inverted is settled at a very early stage of embryonic life, corresponding with the 3rd week of human development. It must be even earlier when there is a genetic cause. Three of the other malformations are settled at or before the end of the 5th week, and bilateral superior vena cava towards the end of the 7th week.

The close association of these malformations is, we think, explained because situs inversus is a predisposing cause of the other four, though they can occur without it. A symmetrical liver does so very rarely, splenic agenesis does so sometimes, and the two venous malformations do so more often, though they are commoner with situs inversus than with a normal situs.

All these malformations are specially liable to occur when the situs is neither completely inverted nor completely normal. Splenic agenesis generally occurs, and a symmetrical liver nearly always occurs, under these conditions.

We have suggested some possible but speculative explanations as to how splenic agenesis and a symmetrical liver may be produced by the vascular changes found with situs inversus.

Our thanks are due to Professor Colin Wendall-Smith of Sydney for most helpful letters and for many references, to Biörn Ivemark of Stockholm for sending us 
"Implications of Agenesis of the Spleen" in 1956, and to Richard Van Praagh of Boston for stimulating discussions in person and by letter. We should like to thank the Librarian of the Zoological Society of London for allowing us to read the fournal of Experimental Zoology in their library.

\section{REFERENCES}

Anderson, R. C., Adams, P., and Burke, B. (1961). Anomalous inferior vena cava with azygos continuation. $\mathcal{f}$. Pediat., 59, 370.

Bacon, R. L. (1945). Self-differentiation and induction in the heart of Amblyostoma. F. exp. Zool., 98, 87.

Baker-Cohen, K. F. (1961). Visceral and vascular transposition in fishes, and a comparison with similar anomalies in man. Amer. F. Anat., 109, 37.

Campbell, M. (1961). Twins and congenital heart disease. Acta Genet. med. (Roma), 10, 443.

- (1963). The mode of inheritance in isolated lævocardia and dextrocardia and situs inversus. Brit. Heart $\mathcal{F}$., 25, 803.

- , and Deuchar, D. C. (1954). The left-sided superior vena cava. Brit. Heart F., 16, 423.

$\longrightarrow$, and - (1965). Dextrocardia and isolated lævocardia. I: Isolated lævocardia. Brit. Heart f., 27, 69.

$\longrightarrow$, and - (1966). Dextrocardia and isolated lævocardia. II: Situs inversus and isolated dextrocardia. Brit. Heart F., 28, 472.

—, Gardner, F., and Reynolds, G. (1952). Cor biloculare. Brit. Heart $\mathcal{F}$., 14, 317.

Copenhaver, W. M. (1926). Experiments on the development of the heart in Amblyostoma punctatum. f. exp. Zool., 43, 321.

Downing, D. F. (1953). Absence of the inferior vena cava. Pediatrics, 12, 675.

Dupuis, C., Nuyts, J. P., and Christiaens, L. (1964). " Continuation azygos" de la véine cave inférieure. Arch. Mal. Cour, 57, 28.

Dwight, T. (1901). Absence of the inferior cava below the diaphragm. F. Anat. Physiol. (Lond.), 35, 7.

Ekman, G. (1924). Neue experimentelle Beiträge zur frühesten Entwicklung des Amphibienherzens. Commentat. biol. Soc. Scient. Fenn., 1, no. 9.

Fales, D. E. (1946). A study of double hearts produced experimentally in embryos of Amblyostoma punctatum. f. exp. Zool., 101, 281.

Goss, G. M. (1935). Double hearts produced experimentally in rat embryos. F. exp. Zool., 72, 33.
Gray's Anatomy (1962). 33rd edn., ed. D. V. Davies and F. Davies. Longmans, London.

Griffith, T. W. (1891). A case of transposition of the thoracic and abdominal viscera with congenital malformation of the heart and certain abnormalities of the arterial and venous systems. F. Anat. Physiol. (Lond.), 26, 117.

Hamilton, W. J., Boyd, J. D., and Mossman, H. W. (1962). Human Embryology, Prenatal Development of Form and Function, 3rd ed. Heffer, Cambridge.

Ivemark, B. I. (1955). Implications of agenesis of the spleen on the pathogenesis of cono-truncus anomalies in childhood. Acta paediat. (Uppsala), 44, Suppl. 104.

Kark, W. (1963). Abnormal persistence of left posterior cardinal vein with clinical manifestations. $\mathcal{f}$. roy. Coll. Surg. Edinb., 8, 145.

Latimer, H. B., and Virden, H. H. (1944). A case of complete absence of the inferior vena cava. $\mathcal{F}$.Kans. med. Soc., 45, 346.

McClure, C. F. W., and Butler, E. G. (1925). The development of the vena cava inferior in man. Amer. $\mathcal{F}$. Anat., 35, 331

- , and Huntington, G. S. (1929). The mammalian vena cava posterior. Amer. anat. Mem., No. 15. Wistar Institute, Philadelphia.

Muelheims, G. H., and Mudd, J. G. (1962). Anomalous inferior vena cava. Amer. F. Cardiol., 9, 945.

Ongley, P. A., Titus, J. L., Khoury, G. H., Rahimtoola, S. H., Marshall, H. J., and Edwards, J. E. (1965). Anomalous connection of pulmonary veins to right atrium, associated with anomalous inferior vena cava, situs inversus and multiple spleens: a developmental complex. Mayo Clin. Proc., 40, 609.

Sanders, J. M. (1946). Bilateral superior vena cavæ. Anat. Rec., 94, 657.

Seib, G. A. (1934). The azygos system of veins in American whites and American negroes, including observations on the inferior vena cava. Amer. F. phys. Anthropol., $19,39$.

Stackelberg, B., Lind, J., and Wegelius, C. (1952). Absence of inferior vena cava diagnosed by angiocardiography. Cardiologia (Basel), 21, 583.

Tihen, J. A., Charles, D. R., and Sippel, T. O. (1948). Inherited visceral inversion in mice. $f$. Hered., 39, 29.

Torgersen, J. (1950). Situs inversus, asymmetry, and twinning. Amer. F. hum. Genet., 2, 361.

Van Praagh, R., Van Praagh, Stella, Vlad, P., and Keith, J. D. (1964). Anatomic types of congenital dextrocardia: diagnostic and embryologic implications. Amer. f. Cardiol., 13, 510.

Willis, R. A. (1962). The Borderland of Embryology and Pathology, 2nd ed. Butterworths, London. 